\title{
Radiofrequency, microwave, and laser ablation of liver tumors: time to move toward a tailored ablation technique?
}

\author{
Paola Tombesi, Francesca Di Vece, Sergio Sartori \\ Department of Medical, Section of Interventional Ultrasound, St. Anna Hospital, 44100 Ferrara, Italy
}

Address for correspondence:

Dr. Sergio Sartori, Department of Medical, Section of Interventional Ultrasound, St. Anna Hospital, Via A. Moro, 44100 Ferrara, Italy. E-mail: srs@unife.it

Received: 03-02-2015, Accepted: 06-04-2015

\section{INTRODUCTION}

Primary and secondary hepatic tumors are quite common and constitute a significant source of mortality. Primary liver cancer is the fifth most common cancer worldwide and the third most common cause of cancer mortality, and secondary involvement of the liver, particularly from colorectal carcinoma, is even more common..$^{[1,2]}$

Although surgical resection remains the gold standard for eligible patients with hepatocellular carcinoma (HCC) or liver metastases (LM), and liver transplantation is considered the standard therapy for selected patients with HCC, in the last years the role of ablation therapies in the treatment of primary and secondary liver tumors continued to increase, as they have widely been proven to be effective and safe..$^{[3-10]}$ They play a key role in the treatment of patients who are not eligible, poor candidates for surgery, or who refuse surgery and are increasingly used as a bridge to liver transplantation in patients with HCC. In addition, some recent studies suggested that radiofrequency ablation (RFA) is as effective as surgical resection in the treatment of very early HCC. ${ }^{[11,12]}$ Depending on tumor size and number, thermal ablation can be chosen as the only treatment, combined with systemic therapies, surgery, or other regional treatments, in order to utilize a multimodality approach to the patient aimed at the best treatment result.

\begin{tabular}{|l|c|}
\hline \multicolumn{2}{|c|}{ Access this article online } \\
\hline \multirow{2}{*}{ Website: } & Quick Response Code \\
http://www.hrjournal.net/ & \\
DOI: & \\
10.4103/2394-5079.155697 & \\
&
\end{tabular}

Thermal ablation techniques include either heating ablation [RFA, microwave ablation (MWA), laser thermal ablation (LTA), and high-intensity focused ultrasound] or freezing ablation (cryoablation). This paper will deal with the "hot" ablation techniques, focusing on RFA, MWA, and LTA. RFA is the most used technique worldwide, and its efficacy has been largely proven over the last 20 years. However, a lot of clinical studies suggest that MWA and LTA are as effective as RFA, and the choice of the thermal ablation modality is usually determined by the experience and preference of the interventional oncologists and radiologists, as well as by the availability of the different devices in the single centers. ${ }^{[13-16]}$ RFA, MWA, and LTA share some main technical aspects. In brief, all of them rely on controlled thermal energy delivery aimed at raising the tissue temperature between $60{ }^{\circ} \mathrm{C}$ and $100^{\circ} \mathrm{C}$ to determine coagulative necrosis of tumor lesions, ${ }^{[17,18]}$ as well as the placement of a needle (RFA electrode, MWA antenna, or LTA fiber through a fine needle) into the target lesion. On the other hand, each thermal technique shows peculiar advantages and limitations that could make each of them more suitable than the other ones to treat patients and tumors with different characteristics.

Therefore, the opening question of this paper is the following: is it time to move toward a tailored approach to thermal ablation?

\section{RADIOFREQUENCY ABLATION}

RFA is based on alternating current of RF waves. The alternating current transmitted via an insulated electrode tip inserted into the tissue generates ionic agitation and frictional heats that extend into adjacent tissue by conduction. When temperature $>60{ }^{\circ} \mathrm{C}$ is achieved, the tissue heating results in coagulative necrosis of the tumor. 
RFA is the most used ablative modality worldwide, and its effectiveness and safety have been fully proven. ${ }^{[3]}$ It is an established therapeutic choice for non-surgical patients with early stage HCC, and some recent papers suggested that RFA can be as effective as surgical resection in terms of overall survival and recurrence-free survival rates in patients with small, centrally located HCC. ${ }^{[11,12]}$ RFA has also been reported to be an effective treatment of $\mathrm{LM} \leq 3 \mathrm{~cm}$, in particular from colorectal cancer, ${ }^{[8,9,19]}$ and it may be indicated in resectable lesions as an adjunct to resection, in inoperable lesions that demonstrate complete or partial response after chemotherapy, or in recurrent and progressive lesions. ${ }^{[18,20]}$

The efficacy of RFA is influenced by tumor location and size. RFA of HCC $<3 \mathrm{~cm}$ diameter achieves complete response in over $90 \%$ of cases, whereas $50-70 \%$ of tumors $3-5 \mathrm{~cm}$ in size are completely ablated. RFA of $\mathrm{HCC}<5 \mathrm{~cm}$ can achieve equal survival benefit compared with surgical resection whereas results for ablation of HCC larger than $5 \mathrm{~cm}$ are poor. ${ }^{[21-23]}$ Reported rate of mortality of percutaneous RFA is $<1 \%$, and major complication rate ranges from $0.6 \%$ to $8.9 \%$. ${ }^{[24,25]}$

\section{Advantages of RFA}

RFA is the best established and well experienced thermal technique among all the thermal modalities available. Its efficacy, feasibility, and safety have been largely proved.

\section{Limits of RFA}

Large lesions can require multiple overlapping ablations to create an adequate safety margin. Although it has recently been reported that the treatment of sub-capsular or high-risk located nodules does not increase the rate of treatment-related complications, ${ }^{[26]}$ the sub-capsular or high-risk position of the nodules can represent a relative contraindication to RFA. Tumors strictly close to large vessels can be incompletely treated due to the heat-sink effect, in which thermal energy produced by ablation is partially shunted away from the tumor by the cooler blood. ${ }^{[27,28]}$

\section{MICROWAVE ABLATION}

MWA utilizes MW frequency (typically at 900-2,500 MHz) to cause oscillation of polar molecules in tissue (primarily water), increasing their kinetic energy and the temperature of the tissue. Although the final effect of MWA consists in coagulative necrosis of the lesion like RFA, the mechanism of heating differs substantially, since MW energy radiates into the tissue through an interstitial antenna that determines direct heating of the lesion. Whereas RF heating requires an electrically conductive path, MWs can propagate even through tissues with low electrical conductivity, high impedance, or low thermal conductivity, like charred or desiccated tissues. ${ }^{[29,30]}$ MW can generate very high temperatures inside the lesion in a very short time, potentially leading to improve treatment efficacy and to obtain larger ablation volumes.

However, the use of MWA was limited for a long time because of technical limitations of some currently available MW systems. Major limitations included low power, shaft heating, large diameter probes (13-14 gauge), small ablation areas requiring multiple insertions, and non-spherical ablation volumes, which have discouraged clinical application of MWA in many western countries. Adding a cooling jacket around the antenna was demonstrated to decrease cable heating, thus increasing the amount of power that can be safely delivered. ${ }^{[31]}$ The introduction of a choke coil into the distal portion of the antenna was also proposed to decrease back heating effects, but this remedy caused remarkable thickening of the antenna, making the devices unsuitable for the percutaneous application. Recently, a miniaturized device has been developed (the so-called Mini Choke $\left.{ }^{\circledR}\right)$, which minimizes the back-heating effects using slender MW antennas (14-16 gauge), and allowing for the percutaneous application. ${ }^{[32]}$

Several prior studies demonstrated that early-generation MWA had equal effectiveness, safety, and survival when compared with RFA, with shorter ablation time. ${ }^{[13,33-35]}$ The recent technical advances (in particular, the Mini Choke ${ }^{\circledR}$ ) have been reported to achieve coagulation of areas larger than RFA. ${ }^{[36-38]}$ Such a capability could result useful in the treatment of tumors $\geq 3 \mathrm{~cm}$. A randomized prospective comparison of MWA and RFA in the treatment of HCC did not demonstrate any difference in the rates of residual or untreated disease, ${ }^{[39]}$ and a local control rate up to $95 \%$ over a median follow-up of 33 months was reported in the intraoperative treatment of colorectal LM. ${ }^{[40]}$ Mortality and major complication rates using the most recent MWA devices are similar to RFA. ${ }^{[32]}$

\section{Advantages of MWA}

MWA offers some advantages compared with RFA, including greater intratumoral temperature, deeper penetration of energy, propagation across the poorly conductive tissue, less sensitivity to the heat-sink effect, and larger ablation volume. Such peculiarities enable to treat larger tumors with adequate safety margin, and nodules closed to large vessels. In addition, MWA does not need the use of grounding pads.

\section{Limits of MWA}

Microwave energy is more difficult to distribute than RF energy. MW energy is carried in wavelengths, which are more cumbersome than the small wires used to feed energy to RF electrodes, and are prone to heating when carrying large amount of power. Consequently, MWA appears less 
feasible than RFA in the treatment of high-risk located and subcapsular nodules. In addition, MWA is more expensive than RFA and LTA.

\section{LASER ABLATION}

LTA utilizes laser devices that convert electrical into light energy, which determines tissue heating and cellular death by coagulative necrosis. Neodymiun: Yttrium aluminum garnet (wavelength of 1,064 nm) and diode (wavelength of $800-980 \mathrm{~nm}$ ) lasers are most commonly used, as penetration of light is optimal in the near infrared spectrum. Light is delivered via flexible bare tip fibers with a diameter from 300 to $600 \mu \mathrm{m}$. A bare-tip fiber provides an almost spherical thermal lesion of $12-15 \mathrm{~mm}$ in diameter, and a beam-splitting device or a multi-source device allows the use of up to four fibers, simultaneously delivering the light into each single fiber. ${ }^{[15-17]}$ The optical and thermal characteristics of the tissue, as well as the proximity of blood vessels, determine the thermal diffusion of the light energy and define the ablation area. Bare tip fibers are inserted through 21-gauge needles into the lesions. Usually, one to two fibers are used to treat nodules up to $1.5 \mathrm{~cm}$ in diameter, three fibers to treat nodules from 1.5 to $2.5 \mathrm{~cm}$, and four fibers with tips arranged in a square configuration to treat nodules $>2.5 \mathrm{~cm}$. In addition, the pullback technique can be used to treat larger nodules.

LTA has been investigated less vigorously than the other ablation techniques, but it seems to show the same efficacy and safety profile than RFA, with a shorter treatment time per session. ${ }^{[16,17,41-43]}$ Most of the studies on LTA are focused on the treatment of HCC. Using from one to four fibers on the basis of tumor size, the reported complete response rates range from $82 \%$ to $97 \% .{ }^{[44-46]}$ Mortality rate is $<1 \%$, and major complication rate ranges from $0.1 \%$ to $3.5 \%{ }^{[47]}$

\section{Advantages of LTA}

The main advantage of LTA is its feasibility, as LTA utilizes very fine needles to insert the fibers into the lesion. Such a characteristic makes LTA particularly safe for the treatment of nodules with difficult location. Furthermore, the possibility to use from one to four fibers allows to achieve ablation areas different in size, enabling to treat lesions different in size or multiple small lesions in the same session, sparing the normal parenchyma as far as possible. In our experience, LTA is the cheapest ablation technique when up to three fibers are used, and it is cheaper than MWA when four fibers are used.

\section{Limits of LTA}

The correct placement of the fibers can result technically difficult, particularly if more than two fibers are needed and should be performed by very skilled operators. The efficacy of LTA can be limited by the heat-sink effect.

\section{FINAL CONSIDERATIONS}

Surgical resection is the treatment of choice for LM, and liver transplantation, whenever possible, is the best curative option for HCC. However, in recent years thermal ablation therapies have become more and more central in the treatment of liver lesions, as the majority of patients are not eligible for surgery. Moreover, some recent studies suggested that RFA is as effective as surgical resection, or even preferable in selected patients, in the treatment of small HCC lesions. ${ }^{[11,12]}$ Good local tumor control and survival comparable with surgical resection were also reported in subgroups of patients with LM from colorectal and breast cancer. ${ }^{[18,19]}$ Thermal ablation of HCC in patient waiting for liver transplantation can be performed as a bridge to the transplantation. Likewise, thermal ablation combined with resection and/or systemic chemotherapy has been demonstrated to improve the survival in patients with LM.

Thermal therapies are minimally invasive, well tolerated, and demonstrate a very low rate of major complications. Although RFA represents the "historical" and more experienced thermal ablation technique, both MWA and LTA have been demonstrated to be as effective and safe as RFA when performed by skilled operators. ${ }^{[13-16]}$ Therefore, to date in most centers of interventional oncology or interventional radiology the choice of the ablation technique usually depends on the physicians' preference and experience. However, when all the three "hot" ablation techniques are available in a single center, which thermal treatment should be preferred?

Each thermal modality presents peculiar technical characteristics, advantages, and limitations. Likewise, patients can have some contraindications to some ablation technique (for instance, the presence of a pacemaker is a relative contraindication to RFA), and tumors can differ in number, size, and location. It follows that, in our opinion, the choice should be based on the characteristics of the patient, tumor, and ablation techniques. For this purpose, we suggest the algorithm adopted in our Section of Interventional Ultrasound, aimed at tailoring the thermal treatment on the single patient to achieve the best outcome [Figures 1 and 2].

In short, a single nodule $2 \mathrm{~cm}$ or smaller in size can efficaciously be ablated using all the thermal modalities. Both RFA and LTA are cheaper than MWA and should be preferred unless the 


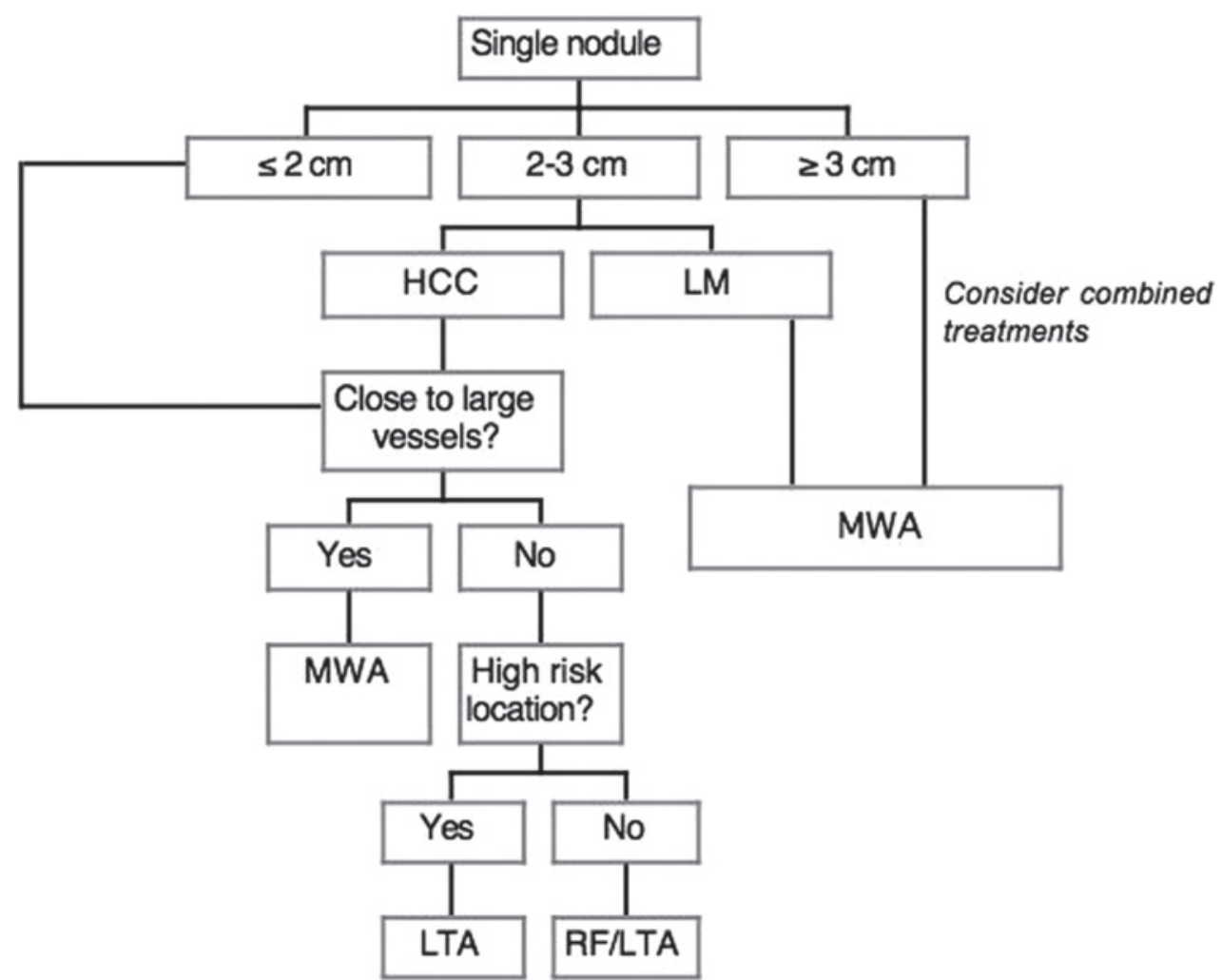

Figure 1: Proposed algorithm for thermal ablation of single nodule. HCC: hepatocellular carcinoma; LM: liver metastases; MWA: microwave ablation; LTA: laser thermal ablation; RF: radiofrequency

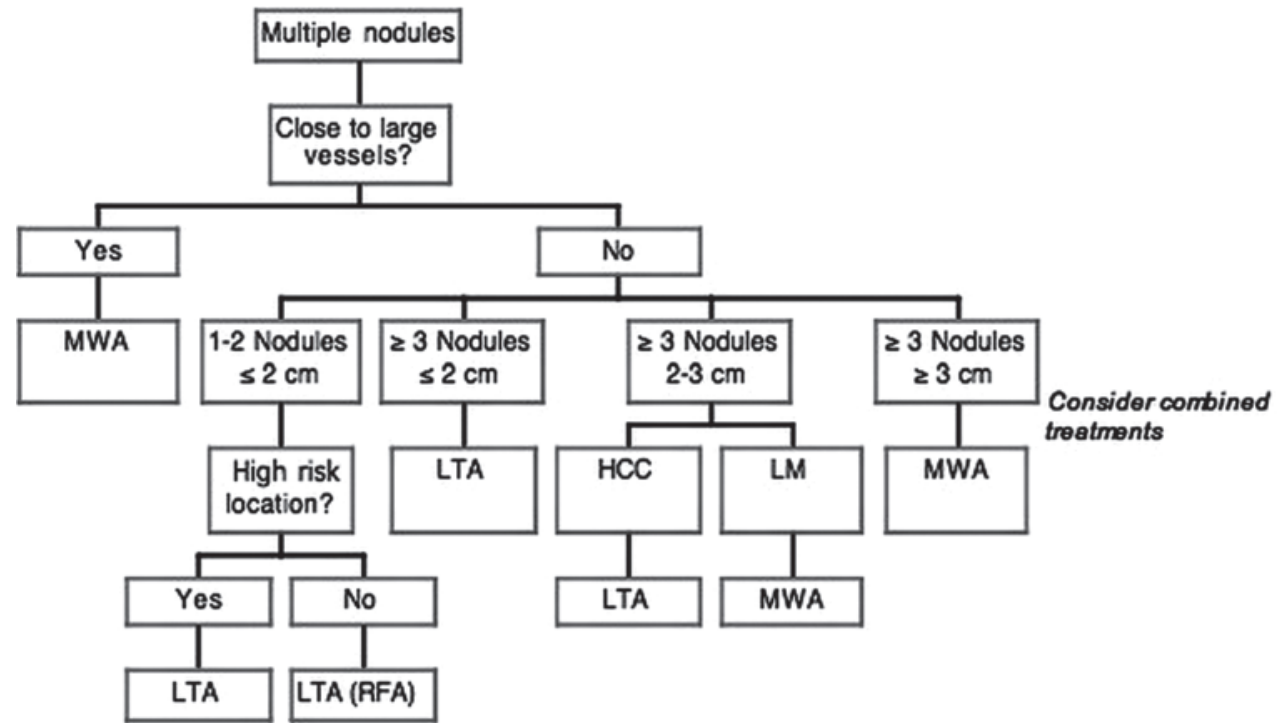

Figure 2: Proposed algorithm for thermal ablation of multiple nodules. HCC: hepatocellular carcinoma; LM: liver metastases; MWA: microwave ablation; LTA: laser thermal ablation; RFA: radiofrequency ablation

tumor is close to large vessels, as MWA is not affected by the heat-sink effect. In addition, LTA could be more feasible and safe when the nodule has a difficult or risky location, as the needles used to insert the fibers are considerably finer than RFA electrodes. Single HCC $2-3 \mathrm{~cm}$ in size could be ablated following the same indications, even though multiple overlapping insertions can be needed for RFA, and at least three fibers should be used for LTA. Conversely, LM $2-3 \mathrm{~cm}$ in size can take advantage of MWA because the safety margin has to be greater than for HCC. Likewise, both single HCC and $\mathrm{LM} \geq 3 \mathrm{~cm}$ should be treated with MWA.

Multiple small lesions (maximum $2.5-3 \mathrm{~cm}$ in diameter), especially if they vary in size, should preferably be treated 
with LTA, as the ablation area can be diversified according to the lesion size using from one to four fibers, thus sparing the normal tissue as far as possible. Finally, MWA should always be preferred when the tumors are close to large vessels or are $\geq 3 \mathrm{~cm}$ in diameter, independently of the number of the nodules.

\section{CONCLUSION}

We have to answer the opening question of this paper. In our own personal opinion, the answer is: yes, it's time to move toward a tailored approach to thermal ablation.

\section{REFERENCES}

1. World Health Organization. Health Statistics and Health Information System. Available from: http//www.who.int/healthinfo/morttables/en/ index.html.

2. Jemal A, Siegel R, Ward E, Hao Y, Xu J, Thun MJ. Cancer statistics, 2009. CA Cancer J Clin 2009;59:225-49.

3. Bruix J, Sherman M; Practice Guidelines Committee, American Association for the Study of Liver Diseases. Management of hepatocellular carcinoma. Hepatology 2005;42:1208-36.

4. Yao FY, Bass NM, Nikolai B, Davern TJ, Kerlan R, Wu V, Ascher NL, Roberts JP. Liver transplantation for hepatocellular carcinoma: analysis of survival according to the intention-to-treat principle and dropout from the waiting list. Liver Transpl 2002;8:873-83.

5. Harmon KE, Ryan JA Jr, Biehl TR, Lee FT. Benefits and safety of hepatic resection for colorectal metastases. Am J Surg 1999;177:402-4.

6. Gervais DA, Goldberg SN, Brown DB, Soulen MC, Millward SF, Rajan DK. Society of Interventional Radiology position statement on percutaneous radiofrequency ablation for the treatment of liver tumors. J Vasc Interv Radiol 2009;20:S342-7.

7. McCarley JR, Soulen MC. Percutaneous ablation of hepatic tumors. Semin Intervent Radiol 2010;27:255-60.

8. Meyer J, Toomay S. Update on treatment of liver metastases: focus on ablation therapies. Curr Oncol Rep 2015;17:420.

9. Gillams AR, Lees WR. Five-year survival following radiofrequency ablation of small, solitary, hepatic colorectal metastases. $J$ Vasc Interv Radiol 2008;19:712-7.

10. Meloni MF, Andreano A, Laeseke PF, Livraghi T, Sironi S, Lee FT Jr. Breast cancer liver metastases: US-guided percutaneous radiofrequency ablation - intermediate and long-term survival rates. Radiology 2009;253:861-9.

11. Peng ZW, Lin XJ, Zhang YJ, Liang HH, Guo RP, Shi M, Shi M, Chen MS. Radiofrequency ablation versus hepatic resection for the treatment of hepatocellular carcinomas $2 \mathrm{~cm}$ or smaller: a retrospective comparative study. Radiology 2012;262:1022-33.

12. Tombesi P, Di Vece F, Sartori S. Resection vs thermal ablation of small hepatocellular carcinoma: what's the first choice? World J Radiol 2013;5:1-4

13. Lu MD, Xu HX, Xie XY, Yin XY, Chen JW, Kuang M, Xu ZF, Liu GJ, Zheng YL. Percutaneous microwave and radiofrequency ablation for hepatocellular carcinoma: a retrospective comparative study. $J$ Gastroenterol 2005;40:1054-60.

14. Shibata T, Niinobu T, Ogata N, Takami M. Microwave coagulation therapy for multiple hepatic metastases from colorectal carcinoma. Cancer 2000;89:276-84.

15. Di Costanzo GG, Francica G, Pacella CM. Laser ablation for small hepatocellular carcinoma: state of the art and future perspectives.
World J Hepatol 2014;6:704-15.

16. Giorgio A, Tarantino L, de Stefano G, Farella N, Catalano O, Cusati B, Del Viscovo L, Alaia A, Caturelli E. Interstitial laser photocoagulation under ultrasound guidance of liver tumors: results in 104 treated patients. Eur J Ultrasound 2000;11:181-8.

17. Francica G, Iodice G, Delle Cave M, Sarrantonio R, Lapiccirella G, Molese V, Smeraldo D, Scarano F, De Marino F. Factors predicting complete necrosis rate after ultrasound-guided percutaneous laser thermoablation of small hepatocellular carcinoma tumors in cirrhotic patients: a multivariate analysis. Acta Radiol 2007;48:514-9.

18. Vogl TJ, Farshid P, Naguib NN, Darvishi A, Bazrafshan B, Mbalisike E, Burkhard T, Zangos S. Thermal ablation of liver metastases from colorectal cancer: radiofrequency, microwave and laser ablation therapies. Radiol Med 2014;119:451-61.

19. Munireddy S, Katz S, Somasundar P, Espat NJ. Thermal tumor ablation therapy for colorectal cancer hepatic metastasis. J Gastrointest Oncol 2012;3:69-77.

20. Govaert KM, van Kessel CS, Lolkema M, Ruers TJ, Borel Rinkes IH. Does radiofrequency ablation add to chemotherapy for unresectable liver metastases? Curr Colorectal Cancer Rep 2012;8:130-7.

21. Chen MS, Li JQ, Zheng Y, Guo RP, Liang HH, Zhang YQ, Lin XJ, Lau WY. A prospective randomized trial comparing percutaneous local ablative therapy and partial hepatectomy for small hepatocellular carcinoma. Ann Surg 2006;243:321-8.

22. Lencioni R, Crocetti L. Image-guided thermal ablation of hepatocellular carcinoma. Crit Rev Oncol Hematol 2008;66:200-7.

23. Kudo M. Local ablation therapy for hepatocellular carcinoma: current status and future perspectives. J Gastroenterol 2004;39:205-14.

24. Livraghi T, Solbiati L, Meloni MF, Gazelle GS, Halpern EF, Goldberg SN. Treatment of focal liver tumors with percutaneous radio-frequency ablation: complications encountered in a multicenter study. Radiology 2003;226:441-51.

25. Giorgio A, Tarantino L, de Stefano G, Coppola C, Ferraioli G. Complications after percutaneous saline-enhanced radiofrequency ablation of liver tumors: 3-year experience with 336 patients at a single center. AJR Am J Roentgenol 2005;184:207-11.

26. Sartori S, Tombesi P, Macario F, Nielsen I, Tassinari D, Catellani M, Abbasciano V. Subcapsular liver tumors treated with percutaneous radiofrequency ablation: a prospective comparison with nonsubcapsular liver tumors for safety and effectiveness. Radiology 2008;248:670-9.

27. Mulier S, Ni Y, Jamart J, Ruers T, Marchal G, Michel L. Local recurrence after hepatic radiofrequency coagulation: multivariate meta-analysis and review of contributing factors. Ann Surg 2005;242:158-71.

28. Lu DS, Raman SS, Limanond P, Aziz D, Economou J, Busuttil R, Sayre J. Influence of large peritumoral vessels on outcome of radiofrequency ablation of liver tumors. J Vasc Interv Radiol 2003;14:1267-74.

29. Brace CL. Radiofrequency and microwave ablation of the liver, lung, kidney, and bone: what are the differences? Curr Probl Diagn Radiol 2009;38:135-43.

30. Schramm W, Yang D, Haemmerich D. Contribution of direct heating, thermal conduction and perfusion during radiofrequency and microwave ablation. Conf Proc IEEE Eng Med Biol Soc 2006;1:5013-6.

31. Wang Y, Sun Y, Feng L, Gao Y, Ni X, Liang P. Internally cooled antenna for microwave ablation: results in ex vivo and in vivo porcine livers. Eur J Radiol 2008;67:357-61.

32. Livraghi T, Meloni F, Solbiati L, Zanus G; Collaborative Italian Group using AMICA system. Complications of microwave ablation for liver tumors: results of a multicenter study. Cardiovasc Intervent Radiol 2012;35:868-74.

33. Simon CJ, Dupuy DE, Mayo-Smith WW. Microwave ablation: principles and applications. Radiographics 2005;25 Suppl 1:S69-83.

34. Boutros C, Somasundar P, Garrean S, Saied A, Espat NJ. Microwave coagulation therapy for hepatic tumors: review of the literature and critical analysis. Surg Oncol 2010;19:e22-32. 
35. Lubner MG, Brace CL, Ziemlewicz TJ, Hinshaw JL, Lee FT Jr. Microwave ablation of hepatic malignancy. Semin Intervent Radiol 2013;30:56-66.

36. Qian GJ, Wang N, Shen Q, Sheng YH, Zhao JQ, Kuang M, Liu GJ, $\mathrm{Wu}$ MC. Efficacy of microwave versus radiofrequency ablation for treatment of small hepatocellular carcinoma: experimental and clinical studies. Eur Radiol 2012;22:1983-90.

37. Cavagnaro M, Amabile C, Bernardi P, Pisa S, Tosoratti N. A minimally invasive antenna for microwave ablation therapies: design, performances, and experimental assessment. IEEE Trans Biomed Eng 2011;58:949-59.

38. Di Vece F, Tombesi P, Ermili F, Maraldi C, Sartori S. Coagulation areas produced by cool-tip radiofrequency ablation and microwave ablation using a device to decrease back-heating effects: a prospective pilot study. Cardiovasc Intervent Radiol 2014;37:723-9.

39. Shibata T, Iimuro Y, Yamamoto Y, Maetani Y, Ametani F, Itoh K, Konishi J. Small hepatocellular carcinoma: comparison of radio-frequency ablation and percutaneous microwave coagulation therapy. Radiology 2002;223:331-7.

40. Ogata Y, Uchida S, Hisaka T, Horiuchi H, Mori S, Ishibashi N, Akagi Y, Shirouzu K. Intraoperative thermal ablation therapy for small colorectal metastases to the liver. Hepatogastroenterology 2008;55:550-6.

41. Pacella CM, Bizzarri G, Francica G, Bianchini A, De Nuntis S, Pacella S, Crescenzi A, Taccogna S, Forlini G, Rossi Z, Osborn J, Stasi R. Percutaneous laser ablation in the treatment of hepatocellular carcinoma with small tumors: analysis of factors affecting the achievement of tumor necrosis. J Vasc Interv Radiol 2005;16:1447-57.

42. Francica G, Petrolati A, Di Stasio E, Pacella S, Stasi R, Pacella CM. Influence of ablative margin on local tumor progression and survival in patients with $\mathrm{HCC} \leq 4 \mathrm{~cm}$ after laser ablation. Acta Radiol 2012;53:394-400.
43. Francica G, Petrolati A, Di Stasio E, Pacella S, Stasi R, Pacella CM. Effectiveness, safety, and local progression after percutaneous laser ablation for hepatocellular carcinoma nodules up to $4 \mathrm{~cm}$ are not affected by tumor location. AJR Am J Roentgenol 2012;199:1393-401.

44. Pacella CM, Bizzarri G, Magnolfi F, Cecconi P, Caspani B, Anelli V, Bianchini A, Valle D, Pacella S, Manenti G, Rossi Z. Laser thermal ablation in the treatment of small hepatocellular carcinoma: results in 74 patients. Radiology 2001;221:712-20.

45. Pacella CM, Francica G, Di Lascio FM, Arienti V, Antico E, Caspani B, Magnolfi F, Megna AS, Pretolani S, Regine R, Sponza M, Stasi R. Long-term outcome of cirrhotic patients with early hepatocellular carcinoma treated with ultrasound-guided percutaneous laser ablation: a retrospective analysis. J Clin Oncol 2009;27:2615-21.

46. Di Costanzo GG, D'Adamo G, Tortora R, Zanfardino F, Mattera S, Francica G, Pacella CM. A novel needle guide system to perform percutaneous laser ablation of liver tumors using the multifiber technique. Acta Radiol 2013;54:876-81.

47. Arienti V, Pretolani S, Pacella CM, Magnolfi F, Caspani B, Francica G, Megna AS, Regine R, Sponza M, Antico E, Di Lascio FM. Complications of laser ablation for hepatocellular carcinoma: a multicenter study. Radiology 2008;246:947-55.

How to cite this article: Tombesi P, Di Vece F, Sartori S. Radiofrequency, microwave, and laser ablation of liver tumors: time to move toward a tailored ablation technique? Hepatoma Res 2015;1:52-7.

Source of Support: Nil. Conflict of Interest: None declared. 